\title{
Automatization of water distribution control for irrigation
}

Irirna F. Yurchenko*

Federal State Budgetary Scientific Institution, Moscow, Russia

\section{ARTICLE IN F O}

\section{Article history:}

Received 31 October 2016

26 January 2017

\section{Keywords:}

Information computer systems

Irrigation
Received in revised form

Accepted 28 January 2017

Automated management

\begin{abstract}
A B S T R A C T
The relevance of research is determined by the need for automation of water distribution in irrigation systems, due to a significant increase in the load on the service Manager water management in connection with the growth of information necessary for the main functional tasks water system, caused by the restructuring of the economic mechanism of the country and the formation of new forms of land ownership and reclamation facilities. The aim of this work is improvement of methods, algorithms and computational and analytical systems computer information technology, ensures stability and uniformity of water delivery and eliminating waste water. Developed computer information technology allocation on inter-farm irrigation network based on the creation of models with the functions: preparation of fragments of planning water distribution decisions and operational management of the water supply; control; informational and technological support of management decision-making; analysis of water use. Solving management problems of water management at inter-farm irrigation systems in the following functional blocks: the formation of the scheme of inter-farm irrigation systems; creating a database of business plans and planning system water use (seasonal and decadal); operational management of water supply; preparation of reports. Implemented the adaptation of the models of water allocation on inter-farm irrigation systems to the conditions of the North Caucasus Federal district, showed the feasibility of their use for the development of indicators of water use under the existing legal and regulatory frameworks functioning water economy complexes of the scope of reclamation.
\end{abstract}

(C) 2017 The Authors. Published by IASE. This is an open access article under the CC BY-NC-ND license (http://creativecommons.org/licenses/by-nc-nd/4.0/).

\section{Introduction}

The improvement of the quality management system of the supply as an important factor in the formation of productivity of agricultural land, associated with the increasing orientation of agricultural producers to maximize the income, what makes them special emphasis in cost saving in the first place, reducing the cost of non-productive losses of water resources.

The adjustment algorithms of water supply management is also due to the technical condition of the equipment, carried out repairs, reconstruction, modernization, requiring periodic evaluation of technically feasible throughput capacity and productivity of water transportation systems, especially because the current flows greatly differ from the design (Pereira et al., 2013; Dinar and Ziberman, 2012; Gutiérrez et al., 2014).

Modernization of irrigation and drainage systems will contribute to the formation of ecological and economic climate change on agro-landscapes, which will create more comfortable conditions for all business entities carrying out their activity on organization of the use of reclaimed land. It will also have a positive impact on the environment of the 


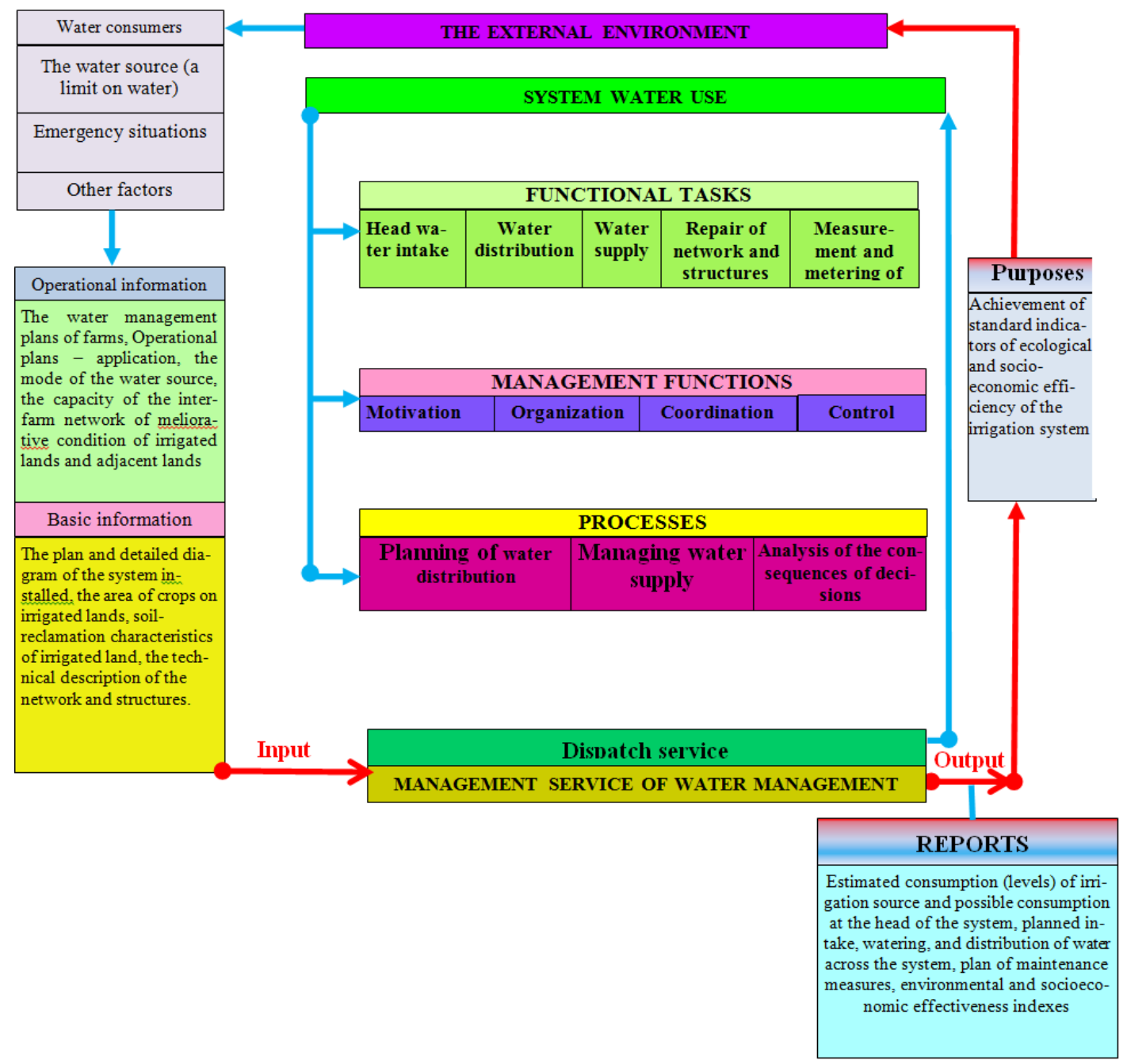

Fig. 1: Schematic diagram of the system of water use

The geography of the North Caucasus Federal district is characterized by mountain landscapes and arid climate, therefore water efficiency is a key challenge. In this regard, the automation and computerization of irrigation and drainage systems will help to increase efficiency, improve the ecological condition of the region and to minimize the financial losses from the incorrect distribution of water resources (Deschka et al., 2013; Shao et al., 2014; Valipour, 2014). The problem of rational use of water resources affects countries with temperate and arid climates, particularly Middle Eastern States.

The purpose of this research is the decision of the scientific problems of automation of task management services to provide the conditions for reliable, fair, impartial distribution of water resources on inter-farm irrigation systems, guaranteeing consistency and uniformity of water supply while minimizing water losses.

New approaches to managing water allocation in a changing environment are based on the creation of computer models of functions: formation of fragments of water distribution planning decisions and operational management of the water supply; control; informational and technological support of management decision-making; analysis of water use, etc. functions.

\section{Methods}

Methodology for automated control of irrigation and drainage systems is based on the theory of irrigation and drainage management, the concept of an integrated automated system of control and support systems in decision-making on the basis of system approach, system research and analysis systems. The article also summarizes the experience of domestic and foreign researchers to consider this issue.

To achieve this purpose, was used the complex of methods of a number of sciences, such as Economics, geography, hydrology. The work also used abstract and logical, historical, analytical and system methods.

\section{Data, analysis, and results}

Computer information technology allocation on inter-farm irrigation network developed by the FEDERAL state scientific institution FSBI "A. N. Kostyakov All-Russian Research Institute of 
Hydraulic Engineering and Land Reclamation" in the research under the research plan approved by the Federal Agency of scientific entities in 2011-2017 gg., is focused on automation of calculation and analytical activities of the dispatch service in the management of the water system. Its mission is to provide multi-criteria assessment system, the implementation of the prognosis and the choice of the most appropriate options of water allocation.

Model water management systems according to information technology build models, consists of describing the structure of the system of water allocation and determining a set of parameters that characterize the system (in this model). The structure of the system of water distribution based on the performance of the system graph, which, due to the nature of the system is a tree. The root of the tree is mapped to the source, and the edges have a direction from the source. System with multiple sources and displays a tree graph with multiple roots, called forest and does not have fundamental differences from of the tree graph. The vertices are numbered in an arbitrary order (usually the numbering starts from the root) and each arc is thus completely characterized by an ordered pair of numbers - the number of the vertex where it goes and the number of the vertex where it is included.
This representation gives the possibility to abstract from unnecessary details and to simplify the display and use of the database model. The arc of the graph correspond to the channels, therefore each arc (i.e., a pair of numbers, numbers its vertices) was mapped to the corresponding channel information. This, for example, a long channel and its efficiency; the maximum capacity of the channel; the seek time from the water intake to the channel outlet to the consumer etc. the vertices of the graph correspond to the locations of flow separation, they are mapped to the parameters of the corresponding complexes of hydraulic structures (GTS), with measuring devices and media.

Building a model water management system is carried out once in the process of setting up software technology to the terms of the function of the operation within a particular irrigation system and can be performed on the basis of specially developed interface to build the model, without reference to the area map, on the basis of the GTS scheme of the irrigation system, using the ACCESS database engine. With the help of the map service to structural model elements can be mapped to geographical coordinates, which further allows visualizing solutions on a map, showing the location of the GTS irrigation system (Fig. 2).

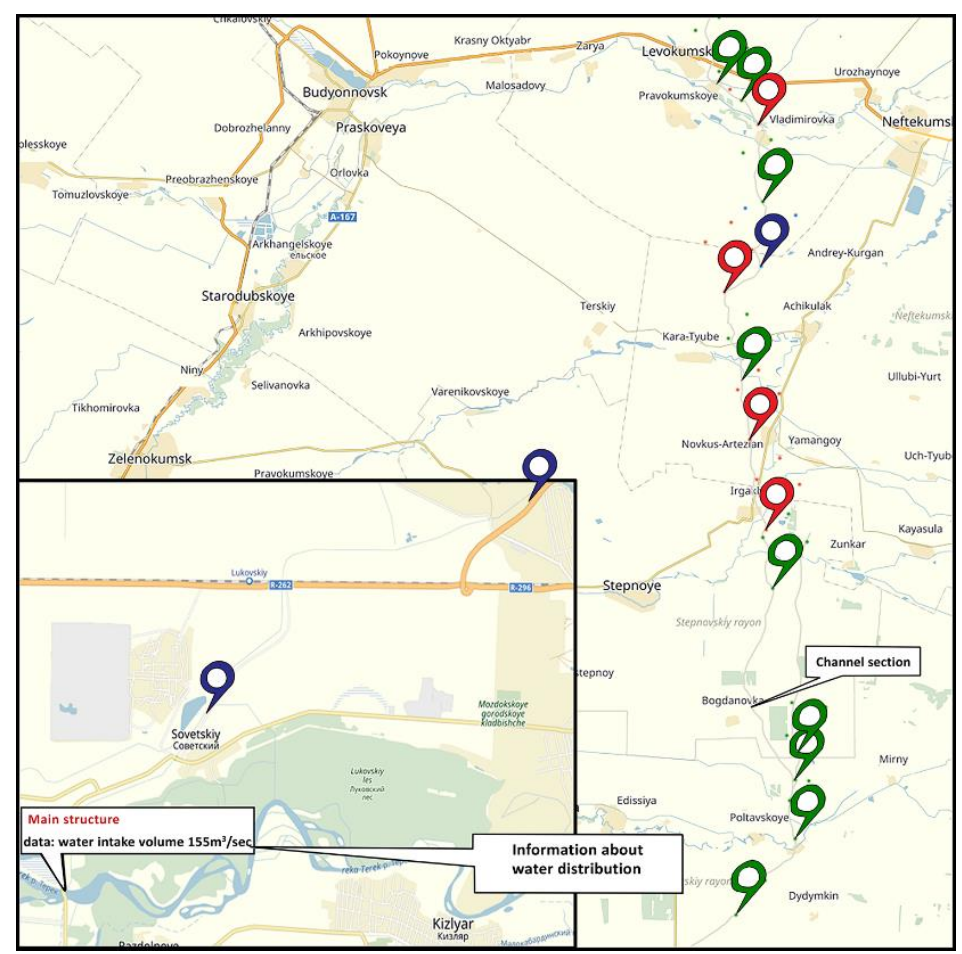

Fig. 2: Displaying on the map the structure of simulated water management system

Software information technology management water distribution should be easy to tune in a completely different geographical location and routine operation of the irrigation system. This is achieved based on our vast database of special models and the corresponding software modules, which can be quite freely combined among them. The basis for the development of this database is based on the following principles:
- Modularity of algorithm development programs;

- Samanmali individual modules;

- Ability to build programs by connecting new modules;

- The possibility of multiple solutions (due to the use of different modules and types of source data, depending on the specific formulation of the problem);

- Information linking tasks within a specific subsystem with other subsystems. 
The choice and arrangement of management software for water distribution followed a few principles and technologies of management:

- In the modeling process, the basic principle of water distribution through the channels adopted a planned Vodopadiki providing the maximum possible satisfaction of customer requirements taking into account stability and sustainability of the water supply for the entire length of the channel while minimizing downtime. Even and equitable water distribution among water users in the contours of inter-farm system is realized by daily (within decades of the vegetation period) planning of water supply that provides a reduction of organizational losses of irrigation water and improving the discipline of water use.

- Water use plans are prepared for the predictable variants of water availability the source of irrigation taking into account variation of weather conditions during the vegetation period and confirmed by results of their consideration by the departments of irrigation systems involved in the management of water use, together with representatives of water users.

- When there is insufficient bandwidth to transport part of the channel or water source of irrigation, causing a shortage of water supply, automated control system provides the definition of the parameters of the deficit of water supply (flow, volume) and the formation of optimal control actions on the object on the basis of technological and economic criteria, distributing the deficiency among the individual consumers, for example, in proportion to the required expenditures. If you encounter defi-lack of reserve capacity source of irrigation or deficit reserve capacity of the channel decreases daily nonuniformity of water consumption. Control system of water distribution in this case is aimed at a systematic organization of the displacement graphs of water consumption of individual water users to reduce water use group graphics to satisfy the condition of non-normalized distribution.

Adaptation of the model: Above we mentioned that the proposed model can be easily adapted to various water distribution systems. This is due to the universality of the General scheme of the model and the simplicity of the formation of the existing base of computing units required for this configuration. A fundamentally important part of adaptation is the selection of its parameters. Some parameters can be measured directly, for example, the length of the channel. Others, although measurable, may change over time. For example, the channel crosses section; in addition, not too easy to measure the parameters of the GTS. The seek time can be computed based on rather complex mathematical models, but the validity of the information thus negated the need to calculate the parameters change rapidly with time, the channel should be described in great detail, piece by piece. In adapting our model we used essentially the method of regression analysis - use the model (ratio) as regression, and the regression parameters computed from the real data. For non-linear regression characterized by the use of methods of minimization of functions of many variables with constraints. The efficacy of this procedure we increase the fact that starting to search for the minimum (i.e. the current values of the numerical parameters of the model) with close values, which are defined by simplistic, standard methods (using the geometry of the channels, their cross sections, etc.). or expert way. Moreover, the appropriate calculations are done periodically, because most of the system parameters change with time. These changes should from time to time to put into the model to improve its compliance with the current state of the system.

Prediction and assessment of the system: The evaluation of the dynamic performance of the system on the basis of previous performance and, in particular, their prediction is an important element of control and optimization. In this case, different groups of parameters and indicators have different importance in the assessment of the system:

- As described above, the estimation of current parameters of the model necessary to simulate processes and, consequently, improve the quality of governance. At the same time, the direction of the "drift of parameter values" may indicate the gradual and be preceded by the violation of operating modes. In this regard, the possibility on the basis of existing time series change parameters to predict their trend (their evolution). We adopted the model of forecasting the Box-Jenkins model is the autoregressive integrated moving average taking into account the external factor. Projected for the long-term values of the model parameters can show the time when the system fails.

- If the parameters are such that the trend does not exist, the parameter values are random variable, taking values, respectively, of some distribution functions. If the distribution functions of the normal law, then the deviation of the current values from the average value more than 3 Sigma may indicate a disadvantage of this subsystem. Therefore, for example, can behave in daily relative values of the real consumption.

- The prediction can even be plans for irrigation, produced in the result in fact of the expert decisions. Significant difference from the forecast can cause checking on the possibility of error.

Misalignment actually achieved with the planned water distribution is a random variable, which, however, is also subject to the forecast. In the next stage of planning consumption values shall be calculated taking into account the predicted distortion. 
The choice of software and technological platform that implements a computer system implemented according to the analysis of current trends in approaches to development of information management systems (Eom, 1995; Ginzberg and Stohr, 1983). In addition to the traditional author of the software, executed by means of Microsoft Office, and some standard nonlinear regression analysis, the composition of the NIR was implemented in a software system, created on the basis of cloud technologies. The latter provide the user dynamic access to services and computing resources, including operating systems and infrastructure, the Internet as an "online service". The version of the software of management information system of water distribution is made on the basis of the service cloud, Google Applications for Business with tailored for cloud services Java programming language Script, showed the advantages of:

- In terms of cost savings due to the lack of need for the construction of local hardware at the dispatch center;

- Level of reliability and security of the system achieved by using technologies to protect the information provided by the company service provider hosting and maintenance of web applications;

- Ensure the most rapid communication with the consumer;

- Improve the efficiency of maintenance by the developer of the software product at the operation stage, due to the possibility of remote work without loss of functional properties.

- Cooperation of the water user and the operator, ensuring the maximum possible transfer rate filings for the operator and their incorporation into the work, automatic electronic documentation of information from water users;

- Ensure the system is in automatic mode even in the absence of the operator in the workplace;

- Reduce "routine" load on the operator and the liberation of decision-makers, to work directly on operational planning and control;

- The lack of associating a user to a specific personal computer

\section{Discussion}

Computer information technology allocation on inter-farm irrigation network has been successfully tested in conditions of experimental - industrial tests to solve the pressing problems of water use at the sites of operation of the following organizations reclamation of water-economic complex of the North Caucasian Federal district:

- Models of operational planning, control and accounting implemented for allocation on Kuma the waterworks and Cognisco Vodohranilishe subordinate Federal State Budget Institute "Administration of Maintenance of Tersk-Kumsk
Hydro system" of Stavropol territory (the Federal State Budget Institute "Administration of Maintenance of Tersk-Kumsk Hydro system"), the implementing organization of JSC "Sevkavgiprovodhoz", Pyatigorsk;

- Seasonal scheduling of water distribution at the inter-Republican canals embedded in FGBU "Management manual interrepublican trunk" of Kabardino-Balkarian Republic (Federal State Budget Institute "Administration of Maintenance of Tersk-Kumsk Hydro system"), the implementing organization of Federal State Budget Institute "Administration of Maintenance of Tersk-Kumsk Hydro system", Dzhulat;

- Planning seasonal and operational water distribution and water supply management adapted to the Federal State Budget Institute "Administration of Maintenance of Tersk-Kumsk Hydro system" in the Republic of North Ossetia Alania (Federal State Budget Institute "Administration of Maintenance of Tersk-Kumsk Hydro system"), the implementing organization of Federal State Budget Institute "Administration of Maintenance of Tersk-Kumsk Hydro system", Mozdok.

These objects and reclamation of water sector provide inter-system, inter-Republic and inter-farm water allocation and can serve as analogues of interfarm irrigation systems.

In conducting reclamation should implement a complex of environmental measures aimed at protecting land and water resources (Worthington, 2013). Computerization of the distribution will contribute to the accurate calculation of the required amount of water for the agricultural sector, without harming the environment.

\section{Conclusion}

Improving the management of water distribution at inter-farm irrigation system through the modernization of algorithms of solving the main tasks of water use increases the efficiency of labor dispatch service operation. In addition, this will significantly reduce the number of accidents on the production, increase the level of productivity, thanks to the rational distribution of water resources, and improve the environment.

Information automated technology designed for water-management organizations, Executive authorities and oversight ensuring the operation and management of water distribution at inter-farm irrigation systems.

Developed by FSBI "A. N. Kostyakov All-Russian Research Institute of Hydraulic Engineering and Land Reclamation" software complex computerbased information technology allocation on interfarm irrigation network has maximum flexibility, allowing you to implement a model of distribution considering virtually any specifics of the differences of irrigation systems by geographical location of GTS 
and routine operation of inter-farm irrigation systems.

\section{References}

Alam MM and Wagner C (2016). The relative importance of monetary and non-monetary drivers for information and communication technology acceptance in rural agribusiness. Information Technology for Development - Special Issue: Conceptualizing and Researching the Socio-Economic Development Impact of ICT, 22(4): 654-671.

Deschka H, Erler S, El-Ayoubi L, Vogel C, Vöhringer L, and Wimmer-Greinecker G (2013). Suction-irrigation drainage: an underestimated therapeutic option for surgical treatment of deep sternal wound infections. Interactive Cardiovascular and Thoracic Surgery, 17(1):85-89.

Dinar A and Zilberman D (2012). The economics and management of water and drainage in agriculture. Springer Science and Business Media, Berlin, Germany.

Eom SB (1995). Decision support systems research: reference disciplines and a cumulative tradition. Omega, 23(5): 511-523.

Ginzberg MJ and Stohr EA (1983). A decision support: Issues and Perspectives- Processes and tools for decision support. NorthHolland Publ. Co., Amsterdam, Netherlands.

Gutiérrez J, Villa-Medina JF, Nieto-Garibay A, and Porta-Gándara MÁ (2014). Automated irrigation system using a wireless sensor network and GPRS module. IEEE Transactions on Instrumentation and Measurement, 63(1): 166-176.

Kydyrova ZS, Satymbekova KB, Kerimbek GE, Nurgalieva AA, Ilyas AA, Zhalbinova SK, and Kanafina AT (2016). Entrepreneurship development and business climate of Kazakhstan. International Journal of Environmental and Science Education, 11(14): 6381-6393.

Matveev YV, Valieva EN, Trubetskaya OV, and Kislov AG (2016) Globalization and regionalization: Institution aspect. Mathematics Education, 11(8): 3114-3126.

Pereira LS, Feddes RA, Gilley JR, and Lesaffre B (2013). Sustainability of irrigated agriculture. Springer Science and Business Media, Berlin, Germany.

Shao GC, Deng S, Liu N, Yu SE, Wang MH, and She DL (2014). Effects of controlled irrigation and drainage on growth, grain yield and water use in paddy rice. European Journal of Agronomy, 53: 1-9.

Valipour M (2013). Need to update of irrigation and water resources information according to the progresses of agricultural knowledge. Agrotechnol S10:e001. https://doi.org/10.4172/2168-9881.S10-e001

Valipour M (2014). Future of the area equipped for irrigation. Archives of Agronomy and Soil Science, 60(12): 1641-1660.

Worthington EB (2013). Arid land irrigation in developing countries: environmental problems and effects. Pergamon Press, Oxford, UK. 